\title{
Playing both roles in the trust game
}

\author{
Stephen V. Burks ${ }^{\text {a }}$, Jeffrey P. Carpenter ${ }^{b}{ }^{*}$, Eric Verhoogen ${ }^{c}$ \\ a Economics and Management, Division of Social Sciences, University of Minnesota, Morris, MN, USA \\ ${ }^{\mathrm{b}}$ Department of Economics, Middlebury College, Middlebury, VT, USA \\ c Department of Economics, University of California, Berkeley, CA, USA
}

Received 6 December 2000; received in revised form 15 September 2001; accepted 14 January 2002

\begin{abstract}
This paper examines the effect of subjects playing both roles in a trust game. We compare two information treatments to our replication of the single-role trust game. The treatments alter the point at which participants are told they will play both roles. We find that playing both roles reduces both trust and reciprocity. We also explore relationships between demographic and personality characteristics and decisions in the game. We find that a social-psychological measure of Machiavellian behavior predicts distrust but not a lack of trustworthiness, and that non-white participants trust less in a predominantly white environment, but are no less trustworthy.

(C) 2002 Elsevier Science B.V. All rights reserved.
\end{abstract}

JEL classification: $\mathrm{C} 91 ; \mathrm{C} 92 ; \mathrm{Z} 13$

Keywords: Trust; Reciprocity; Experiment; Norm; Machiavelli

\section{Introduction}

A growing body of work in experimental economics has established that people often behave in ways that are inconsistent with simple maximization of their monetary payoffs. Subjects appear to exhibit "social preferences," or concerns over adherence to a variety of social norms including reciprocity and fairness (Fehr and Schmidt, 1999; Bolton and Ockenfels, 1999; Falk and Fischbacher, 1998; Rabin and Charness, forthcoming). This experimental work has also revealed, however, that subjects' behavior is sensitive to the framing of social interactions in the laboratory. Small differences in the description or procedures of games may cue subjects to follow very different norms, with large consequences for

\footnotetext{
* Corresponding author. Tel.: +1-802-443-3241; fax: +1-802-443-2084.

E-mail addresses: svburks@mrs.umn.edu (S.V. Burks), jpc@middlebury.edu (J.P. Carpenter), everhoog@econ.berkeley.edu (E. Verhoogen).
} 
observed behavior (McCabe et al., 1998; Hoffman et al., 1994, 1996; Eckel and Grossman, 1996; Carpenter, 2002).

In this paper, we explore the effects of modifying the protocol of a standard trust game. In the trust game devised by Berg et al. (1995) (hereafter BDMc), a subject decides either how much to send to a partner initially (the sender role) or how much of the total received to return (the returner role). We present a new game in which each subject plays both sender and returner roles, with different partners. We compare two information treatments to our replication of the basic trust game. In the first treatment, subjects discover that they will play the returner role only after they have made their decisions as senders. In the second treatment, subjects know in advance that they will play both the roles.

Playing both the roles may affect subjects' behavior in a number of ways. If playing both roles prompts subjects to do unto others as they would have done unto them-either because the framing leads subjects to empathize with their partners, or simply because it increases the salience of the golden rule norm-we would expect playing both roles to raise both the degree of trust and the degree of reciprocity exhibited in the game. We call this prediction the golden rule hypothesis. ${ }^{1}$ On the other hand, playing both roles might reduce the degree of trust and reciprocity. For instance, the fact that the payoff for participants in the two-role version of our game depends on the outcomes of two separate interactions-one as sender and one as returner-might lead each participant to feel less responsibility for the well being of her partner in any one of those interactions, and as a result to feel less guilty about acting selfishly. We call this the reduced responsibility hypothesis. ${ }^{2}$

The primary result of our paper is that having subjects play both roles reduces both the degree of trust - measured by the amount sent—and the degree of reciprocity—-measured by the amount returned-in the trust game. This effect is present only when subjects are informed of the two-role structure of the game prior to their decisions. ${ }^{3}$

Previous work on the trust game has found considerable variation in the behavior of individual subjects (Berg et al., 1995; Cox, 1999; Bolle, 1998). A secondary contribution of this paper is to explore the extent to which individual subjects' answers to a variety of survey questions explain this variation. We collect basic demographic information from subjects and ask several questions typically used to measure social capital characteristics. We also employ the "Mach scale", a social-psychological instrument designed to measure the extent to which individuals are predisposed to using guile, deceit and opportunism in their relations with others (Christie and Geis, 1970); previous uses in an economic context include Meyer (1992), and Gunnthorsdottir et al. (2000). We find that the Mach scale predicts distrust but not a lack of trustworthiness. We also find that non-white

\footnotetext{
1 This hypothesis can also be generated from what might be loosely called an impartial reasoning or Rawlsian approach. Behind Rawl's "veil of ignorance" agents do not know what role they will play in a game and therefore have an incentive to ensure their own well being by maximizing the minimum payoff to each role. The analogue in the trust game is to send and reciprocate such that the gain for each role in greater than the US\$ 10 show-up fee. For more on the impartial reasoning approach to distributive dilemmas see Frohlich (1992) and Frohlich and Oppenheimer (1996).

2 There may be other reasons why playing both the roles may lead subjects to display less trust and reciprocity. We return to this question in Section 6.

${ }^{3}$ We were surprised by this result. Our prior expectation was that playing both roles would lead subjects to exhibit both more trust and more reciprocity.
} 
participants exhibited less trust than whites in a mostly white environment, but not less trustworthiness.

\section{The trust game and playing both roles}

In the standard BDMc game, participants are separated into two rooms; call them A and B. Each participant in room A-each "sender"-has the opportunity to send money to an anonymously matched participant in room B. Any money passed from room A to room B is tripled by an experimenter along the way. Each participant in room B-each "returner"then chooses how much to send back. The trust game is played one-shot under double-blind anonymity to prevent investments in reputation or an experimenter effect. Given this set up, the amount sent initially can be taken as a measure of the sender's trust and the amount returned as a measure of the returner's reciprocity or trustworthiness.

If subjects only care about their monetary payoffs, the subgame-perfect equilibrium prediction in this game is straightforward. Returning money reduces the returner's payoff; hence, the returner will never send anything back. Anticipating this, senders will not send money initially. Both players would be at least as well off if the group A player were to send any portion of her endowment and the group B player were to return at least the amount sent, but this potential Pareto improvement is foregone because the B player cannot make a binding commitment to share the surplus.

The BDMc data are inconsistent with the prediction of zero dollars sent initially and zero dollars returned. Group A players tended to trust group B players to return money; they sent an average of US\$ 5.16 out of an initial endowment of US\$ 10. Group B players tended to be trustworthy, at least to some extent; they returned an average of US\$ 4.66. The stylized fact of non-trivial trust and trustworthiness is replicated to varying degrees in Barr (1999), Cox (1999), Fahr and Irlenbusch (1999) and Glaeser et al. (2000).

We are not aware of experiments that examine the effects of having subjects play both roles in the trust game. The evidence on the effects of having subjects play more than one role in other games is mixed. In a binary choice extensive form game similar to a truncated centipede game, Snijders and Keren (1994) found that subjects who were asked to play both roles displayed more trust and trustworthiness than subjects in the single-role version of the game described in Gueth et al. (1997). In the two-stage shrinking pie bargaining experiment conducted by Binmore et al. (1985), participants who initially were assigned the role of the second mover were asked to participate in another session in which they assume the first mover role. The authors found that those subjects who played both roles acted more in line with the subgame-perfect strategy than those who did not. In the ultimatum game, Carter and Irons (1991) and Weg and Smith (1993) found that proposer demands were greater if subjects play both roles, compared with the standard single-role experiment of Forsythe et al. (1994). But Gueth and Tietz (1990), in their survey of ultimatum experiments, found that proposers who play both roles make smaller demands than those who do not. ${ }^{4}$ The

\footnotetext{
4 There are other dual-role experiments (Gueth et al., 1982; Kahneman et al., 1986; Carter and Irons, 1991; Rabin and Charness, forthcoming; Brandts and Charness, 2000), but the designs are not sufficiently similar across papers to allow useful comparisons.
} 
variety of results for other games suggests that an examination of the effect of playing both roles is warranted for the trust game.

\section{Experimental design}

Our experimental procedure is designed to test the sensitivity of the BDMc results to having subjects play both the sender and receiver roles. We ran three treatments. Our control treatment replicated the BDMc procedure. For our second treatment, we developed a new procedure that we call the two-role trust, no prior knowledge game (2RT-NP). In this game, subjects play both the sender and the returner roles, but they are not told they will play the returner role until after the sender decision has been made. The comparison of this treatment with the control allows us to isolate the effect of playing both roles on the behavior of returners. For our third treatment, we use a second new procedure that we call the two-role trust, prior knowledge game (2RT-P). In this game, participants know that they will play both roles before any decisions are made. Comparison of this treatment with the 2RT-NP treatment allows us to isolate the effect of prior knowledge on the decisions of senders. Comparison with the control treatment provides a measure of the combined effect of playing both roles on senders' and returners' decisions.

We now describe the procedures in more detail, beginning with a description of the control treatment. ${ }^{5}$ Our subjects were Middlebury College students who were randomly picked from a list of people responding to an email solicitation for each experimental session. (There were three sessions on consecutive days.) We received all the participants in a common room, which we call room A. As subjects arrived, they signed in and drew the top card from a normal deck of cards, arranged to alternate black and red cards. Once all the participants had shown up, we publicly flipped a coin to decide which group-black card holders or red card holders-stayed in room A and which group went to another room, which we call room $\mathrm{B}$. The experimenter in each room then handed out written instructions and encouraged participants to follow along as he read the instructions aloud.

Subjects in room A were informed that they were senders. Each participant randomly picked a large manila envelope, went into an adjacent room and sat down at an isolated desk (facing a corner or wall) to make her decision privately. Within each large manila envelope was a letter-size white envelope containing ten one dollar bills. Each player A decided how many dollar bills to keep and placed the rest in the smaller white envelope. Each of the smaller white envelopes had a unique number written on it. Participants were asked to remember their numbers; pads of paper on which to note their numbers were provided. The correspondence between these "subject-pair numbers" and the identities of the participants remained unknown to the experimenters at all times; and this was made clear to the participants. When all the sender decisions had been completed, one of the experimenters took the envelopes to a desk in the hallway, where he recorded the amount contained in each smaller envelope by its subject-pair number, tripled the amount and placed

\footnotetext{
5 The instructions for the 2RT-NP treatment are reproduced in their entirety in Appendix A. The instructions for the other two treatments contain identical language. The differences are that in the control treatment, participants were never given the "additional instructions for all participants." In the 2RT-P treatment, participants were given the "additional instructions" prior to making any decisions.
} 
each smaller envelope again in the larger manila envelope. The envelopes were then taken to room B.

Subjects in room B were paid a US\$ 10 show-up fee while the subjects in room A were making their decisions. When the manila envelopes (with the tripled amounts) arrived in room B, each subject chose a manila envelope at random and then decided privately how much of the (tripled) total amount to keep and how much to return to the sender. Again, subjects noted on a slip of paper the number of the smaller envelope they received. When all the returner decisions were completed, one experimenter brought the envelopes back to the hall and recorded the amount returned in each smaller envelope, by its subject-pair number. While this process was occurring, subjects in both the rooms filled out the post-experiment questionnaire, on which each also placed her subject-pair number.

After recording the results, the small envelopes were sealed and returned to room A. Participants went one at a time to a box in the front of the room to retrieve the smaller envelope that they had originally sent. Before the subjects opened the sealed envelopes, we verified that every participant had received the correct envelope. If this was not the case (this happened only once), we collected all the envelopes and went through the process again.

The 2RT-NP treatment differed from the control treatment in that both groups of subjects were assigned to room A (i.e. there were two room As). The instructions read to each group were the same as the instructions read to participants in room A in the control treatment. Participants followed the same steps as the senders in the control treatment in deciding how much money to send. Once all the participants in both the rooms had made their sending decisions, they were informed that they would also play the returner role. They were then given instructions similar to those given to participants in room B in the control treatment.

As participants were being informed of their new role, an experimenter recorded the amounts sent, tripled the amounts and sent each set of manila envelopes on to the room from which it had not come. Participants in both rooms then followed the same steps as the returners in the control treatment in deciding how much money to return. Once all the participants in both the groups had completed their returner decisions, they filled out the post-experiment questionnaire, noting both of their subject-pair numbers. Once the amounts returned had been recorded, the sealed smaller envelopes were returned to the participants following the same procedure as in the control treatment.

The 2RT-P treatment differed from the 2RT-NP treatment only in that subjects were informed before making their sender decisions that they would be playing both roles. In all other ways, the procedure was identical to the 2RT-NP treatment.

\section{Treatment effects}

A total of 130 participants took part in the experiment: 44 in the standard game, 46 in the 2RT-NP game and 40 in the 2RT-P game. Participants earned an average of US\$16.50 in the standard treatment, US\$21.22 in the 2RT-NP treatment and US\$ 18.20 in the 2RT-P treatment. Table 1 reports the means of demographic variables for participants by treatment group (see Appendix B for variable definitions). The means do not differ significantly across the groups, suggesting that our procedure for assigning subjects to treatment groups was indeed random. 
Table 1

Summary statistics for demographic variables

\begin{tabular}{|c|c|c|c|c|c|c|}
\hline \multirow[t]{2}{*}{ Variable } & \multicolumn{2}{|c|}{ Control $(n=44)$} & \multicolumn{2}{|c|}{ No prior knowledge $(n=46)$} & \multicolumn{2}{|c|}{ Prior knowledge $(n=40)$} \\
\hline & Mean & S.D. & Mean & S.D. & Mean & S.D. \\
\hline Age (years) & 20.86 & 1.68 & 20.76 & 1.34 & 20.60 & 1.30 \\
\hline FEMALE & 0.61 & 0.49 & 0.48 & 0.51 & 0.51 & 0.51 \\
\hline NONWHITE & 0.14 & 0.35 & 0.09 & 0.29 & 0.15 & 0.37 \\
\hline MEDU & 16.43 & 1.89 & 16.02 & 2.19 & 16.23 & 1.81 \\
\hline FEDU & 17.18 & 1.73 & 16.67 & 1.80 & 16.95 & 1.65 \\
\hline Family income & 157,273 & 111,613 & 107,778 & 78,303 & 123,333 & 81,205 \\
\hline
\end{tabular}

Table 2

Comparison to BDMc

\begin{tabular}{lllll}
\hline & Control & NO PRIOR & PRIOR & BDMc \\
\hline Average dollars sent & $6.50(3.61)$ & $6.52(3.66)$ & $4.73(3.77)$ & $5.16(2.94)$ \\
Average dollars returned & $8.50(7.99)$ & $5.06(5.94)$ & $2.43(5.75)$ & $4.66(5.55)$ \\
Average fraction returned & 0.40 & 0.25 & 0.14 & 0.30
\end{tabular}

The values in the parentheses indicate the standard deviation.

Table 2 presents a summary of our data in comparison to the BDMc data. The table reports averages of dollars sent and returned, as well as the average amount returned as a fraction of the (tripled) amount received by the returners. In contrast to the BDMc experiments, on average it paid to trust in our control game: senders received US\$ 8.5/6.5 $=1.31$ for each dollar sent to the other room. Perhaps in anticipation of this higher level of trustworthiness, the average sent was higher than the BDMc average. The differences between our results and the BDMc results, however, are not statistically significant. For amounts sent, the Wilcoxon test statistic is $z=1.45$, with $p$-value 0.15 . For fractions returned, the test statistic is $z=$ 1.40 , with $p$-value 0.16 . We conclude that our control treatment protocol elicits behavior similar to that in BDMc's original trust game.

We now turn to the effects of having subjects play both roles in the game, beginning with the effect on the amount sent. Fig. 1 presents histograms of the amounts sent in each of the three treatments. ${ }^{6}$ Comparing Fig. 1(a) and (b), we see that the distribution of amounts sent in the 2RT-NP treatment is similar to the distribution in the control treatment. In Fig. 1(c), we see that the amounts sent decreased in the prior-knowledge treatment. The clear mode in both the standard game and the 2RT-NP game is to send US\$ 9 or 10. The distribution becomes much flatter in the 2RT-P game; there are spikes at sending very little (US\$ 0 or 1 ), and at sending US\$ 5, as well as at sending US\$ 9 or 10.

These observations are confirmed by statistical tests. The Wilcoxon rank-sum statistic for the control versus $2 \mathrm{RT}$-NP comparison is $z=-0.25$, with $p$-value 0.80 , indicating that we

\footnotetext{
${ }^{6}$ Note that any visual comparisons between the control histogram and the treatment histograms should take into account the fact that the number of observations is approximately double in each of the two treatments because the participants played both roles.
} 
cannot reject the hypothesis that the amounts sent are equal. For the 2RT-NP versus 2RT-P comparison, we find $z=2.39$, with $p$-value 0.02 . For the control versus $2 \mathrm{RT}$-P comparison, we find $z=1.73$, with a $p$-value of 0.08 . The latter result is only modestly significant by conventional standards, but we can make use of the fact that there was not a statistically

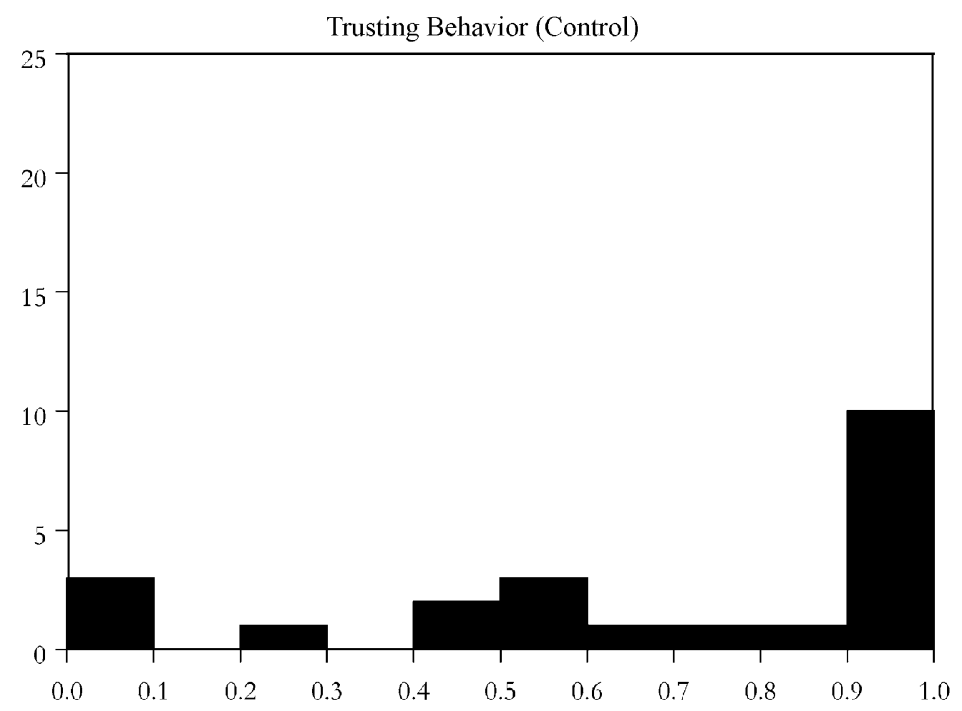

(a)

Fraction of Endowment Sent

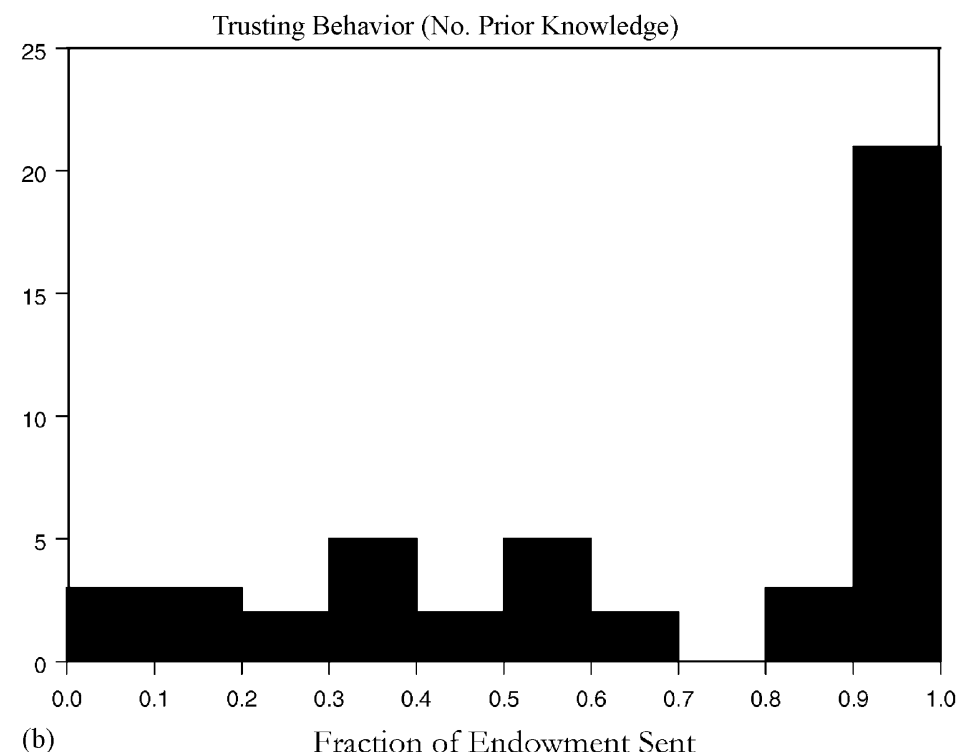

Fig. 1. (a) Trusting behavior (control); (b) Trusting behavior (no prior knowledge); (c) Trusting behavior (prior knowledge). 


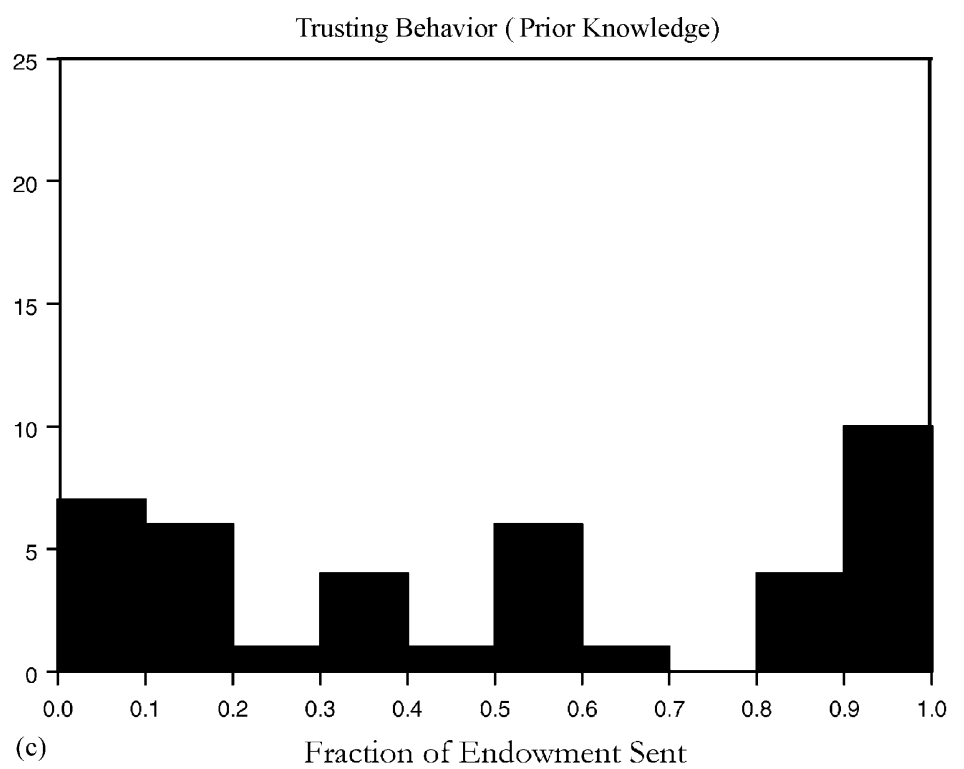

Fig. 1. (Continued).

significant difference in the amount sent between the control treatment and the 2RT-NP game and pool observations from those treatments. When we increase the sample in this way and compare the pooled control/2RT-NP sample to the 2RT-P sample, we find a highly significant result: $z=2.51$, with $p$-value 0.01 . Subjects trusted significantly less when they knew that they would be both a sender and a returner. If the golden rule hypothesis had been correct, we would have expected an increase in the amount sent in the prior-knowledge treatment.

Consider now the effects of the treatments on the amount returned. Fig. 2 presents histograms of the amounts sent back as fractions of the amounts received. Fig. 2(a) reports fractions returned for the control treatment. The most obvious mode is at 50 percent. Using the least complicated fairness heuristic, many returners split what they received in half. There is also evidence supporting the more sophisticated fairness heuristic of splitting evenly the surplus generated by the sender's trust, returning two-thirds of the amount received. ${ }^{7}$ The prevalence of fractions returned in the $0.5-0.7$ range supports the proposition that people exhibit reciprocity in response to being trusted and that the extent of reciprocity is guided by equity considerations. There is also a mode at zero, i.e. at being completely untrustworthy. This behavior of returners in the control treatment is similar to that reported in BDMc.

Fig. 2(b) and (c) present the data on the fractions returned from the 2RT-NP and 2RT-P treatments. It is evident that untrustworthy behavior became more prevalent in the no prior-knowledge treatment and still more prevalent in the prior-knowledge treatment. In the 2RT-NP game, there are still a substantial number of participants who return half the

\footnotetext{
${ }^{7}$ Let $\tau$ be the amount sent, and $3 \tau$ the amount received by the returner. Returning half of the amount received leaves the pair with unequal final payoffs: the sender ends up with $10-\tau+1.5 \tau=10+0.5 \tau$ and the returner with $10+1.5 \tau$. However, returning two-thirds of the amount received makes final payoffs equal $(10+\tau)$.
} 
amount received, but none who split the surplus evenly by returning two-thirds of what was received. The shift is even more pronounced in the 2RT-P game, where almost all the participants keep the entire amount received and only a few return any positive amount. Trusting does not pay, on average, in our two-way treatments. Returning to Table 1, we see

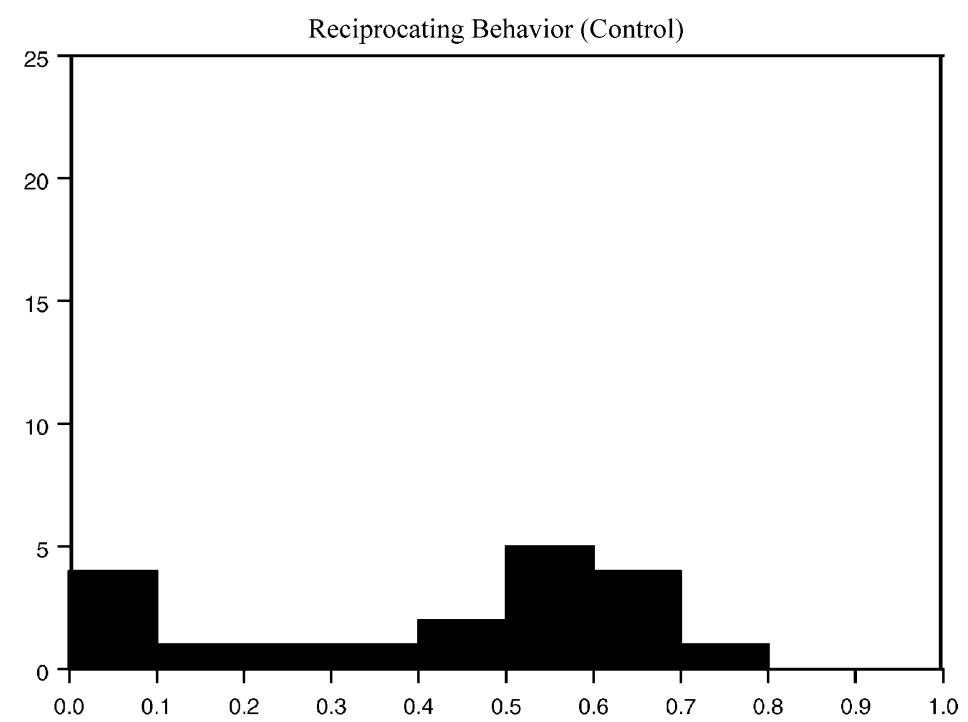

(a)

Fraction Returned

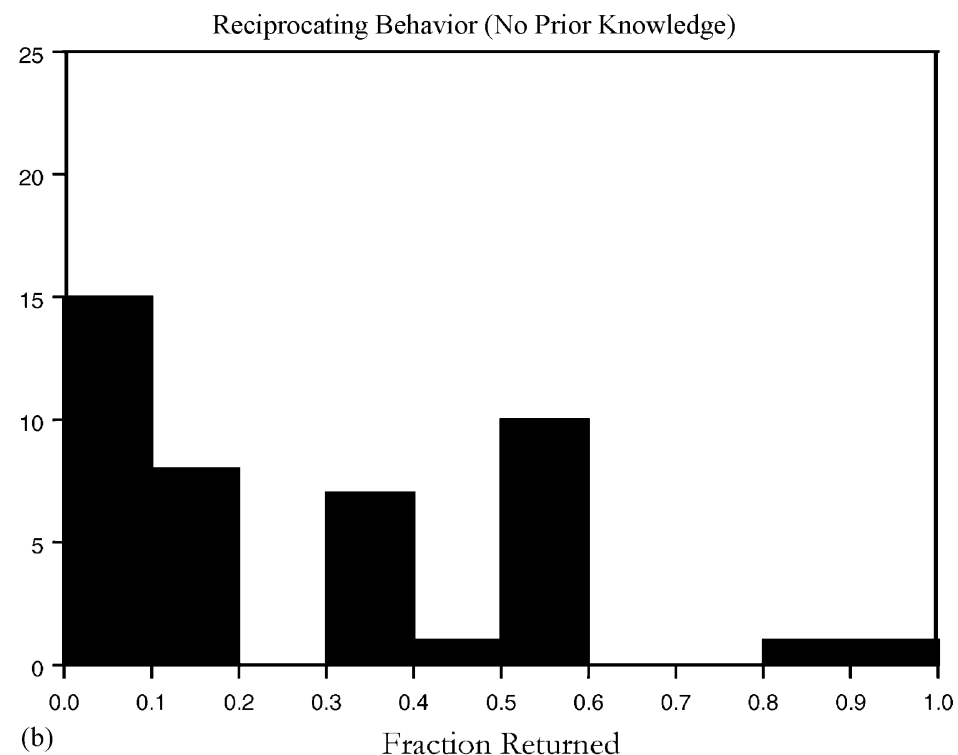

Fig. 2. (a) Reciprocating behavior (control); (b) Reciprocating behavior (no prior knowledge); (c) Reciprocating behavior (prior knowledge). 


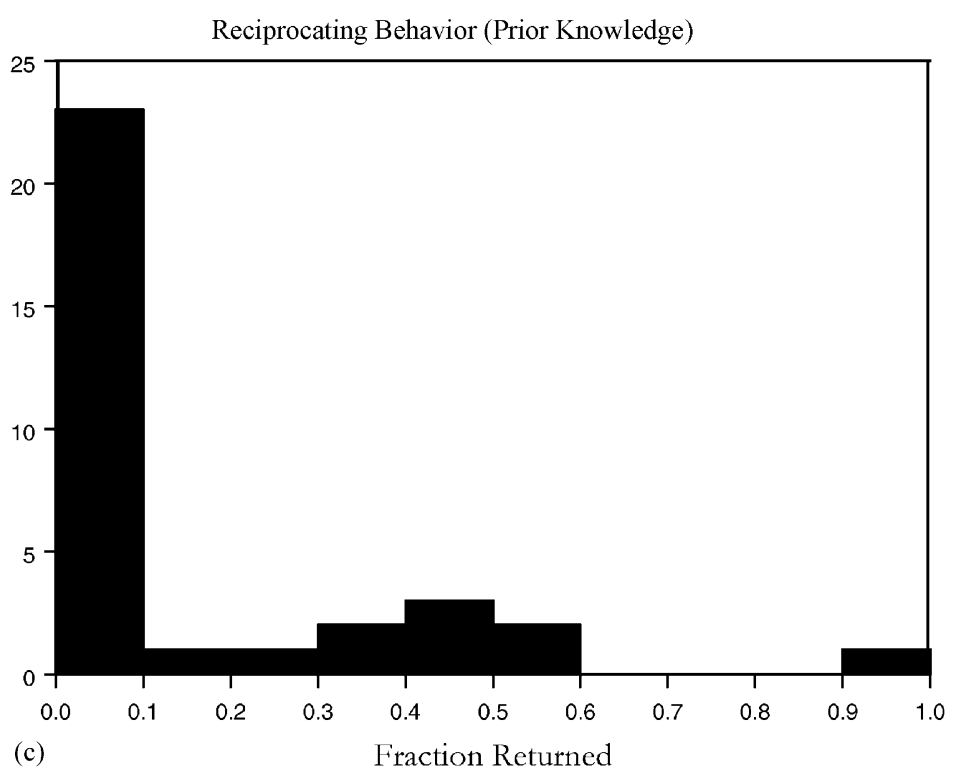

Fig. 2. (Continued).

that the expected payoff from sending US\$ 1 is 75 cents in the 2RT-NP game and only 51 cents in the 2RT-P game. These payoffs are clearly less than in our control treatment and also less than the 90-cent return in the standard BDMc game.

Statistical tests confirm these observations. The differences in fractions returned across treatments are highly significant. Comparing the control treatment with the 2RT-NP treatment, we have $z=2.35$, with $p=0.02$. Comparing the 2RT-NP and the 2RT-P treatments yields $z=2.36, p=0.02$. Finally, comparing the control treatment with the 2RT-P game we find $z=3.67, p=0.0002$. If the golden rule hypothesis had been correct, we would have expected the amount returned to be higher in the two-role treatments than in the control treatment. Note that neither the golden rule nor the reduced responsibility hypothesis predicts the difference we observe in the amount returned between the 2RT-NP and 2RT-P treatments.

These statistical tests assume that there was no "experimenter effect" in our experiments, which may not be justified. One of our objectives in designing our two-role games was to develop a protocol that doubles the amount of data collected and can be easily implemented in field experiments. In practice, this meant that each experimenter answered questions on the instructions and rules of the game aloud, in front of all the participants in a particular room. While we strove to frame the game in neutral way, we cannot rule out the possibility that giving instructions and answering questions aloud may have had the effect of setting a tone in the room that either favored or disfavored trusting or reciprocating behavior and that the tone differed systematically by experimenter.

To test for this possibility, we have to place more requirements on the data generating process than in the non-parametric tests earlier; in particular, we use a linear regression model with additively separable treatment and experimenter effects. Table 3 reports the results. 
Table 3

Controlling for an experimenter effect

\begin{tabular}{lccrr}
\hline & \multicolumn{1}{c}{$(1)$} & $(2)$ & $(3)$ & $(4)$ \\
\hline Constant & $6.50^{* *}(0.76)$ & $6.50^{* *}(0.77)$ & $0.402^{* *}(0.057)$ & $0.386^{* *}(0.075)$ \\
NO PRIOR & $0.02(0.93)$ & $-0.85(1.06)$ & $-0.151^{*}(0.068)$ & $-0.139^{+}(0.075)$ \\
PRIOR & $-1.78^{+}(0.97)$ & $-2.65^{* *}(1.01)$ & $-0.265^{* *}(0.070)$ & $-0.251^{* *}(0.081)$ \\
EXPERIMENTER & - & $1.74^{*}(0.78)$ & - & $0.023(0.058)$ \\
$R^{2}$ & 0.05 & 0.10 & 0.133 & 0.135 \\
\hline
\end{tabular}

OLS with robust standard errors in parentheses; in Columns (1) and (2) the dependent variable is the "amount sent" while in Columns (3) and (4) the dependent variable is the "fraction returned."

+ Significant at 0.10 level.

* Significant at 0.05 level.

** Significant at 0.01 level.

Column (1) confirms the non-parametric tests earlier for amount sent. The coefficient on the 2RT-NP dummy is not significantly different from zero; we do not reject the hypothesis of no difference between the amounts sent in the control and 2RT-NP treatments. The coefficient on the 2RT-P dummy, by contrast, is significant at the 10 percent level and negative. Also, we can reject the hypothesis that the coefficients on the 2RT-NP and 2RT-P treatments are equal at the 5 percent confidence level. Column (2) includes an experimenter dummy. The same two experimenters read the instructions in all treatments. The dummy variable takes the value one for one of the experimenters, and zero for the other. The coefficient on this dummy is positive and statistically significant at the 5 percent level. However, the coefficient on the 2RT-NP dummy remains statistically indistinguishable from zero, and the coefficient on the 2RT-P dummy remains negative and significant at the 1 percent level. Our finding of the negative effect on the amount sent in the prior-knowledge treatment is thus robust to the inclusion of an experimenter effect. Columns (3) and (4) report analogous regressions for fraction returned. Again, the regression in Column (3) confirms our non-parametric results earlier, and Column (4) indicates that our findings for the treatment effects are robust to the inclusion of the experimenter dummy.

\section{Do individual characteristics predict behavior?}

\subsection{Measures of individual characteristics}

In this section, we discuss the relationship between subjects' demographic and personality characteristics and the degree of trust and trustworthiness they exhibited in the trust game. As mentioned earlier, after participants made their sender and returner decisions, but before they discovered how much of the initial amount sent had been returned to them (if applicable), they filled out a survey in which we collected basic demographic information: age, sex, ethnicity, year in college, mother's education, father's education and family income.

We also asked two sets of questions on personality characteristics. One set was the Machiavellian personality test developed by Christie and Geis (1970). The Mach test consists of a series of 20 statements-such as "never tell anyone the real reason you did something 
unless it is useful to do so," or "it is safest to assume that all people have a vicious streak and it will come out when they are given a chance"-to which subjects are asked to agree or disagree, on a seven-point Likert scale. ${ }^{8}$ Those who tend to agree with the Machiavellian statements are termed "high Machs," and those who tend to disagree "low Machs."

The Mach scale is designed to capture three components of an individual's behavioral dispositions: (1) the extent to which a subject has a cynical view of human nature, believing that others are not trustworthy; (2) the willingness of a subject to engage in manipulative behaviors; (3) the extent of the subjects' concern (or lack thereof) with conventional morality (Christie and Geis, 1970; Fehr et al., 1992). The Mach scale is well established in the social psychology literature (McHoskey et al., 1998; Wilson et al., 1996, 1998). Researchers have found both that the scale is reliable, in that individuals' scores vary little from one administration of the test to another, and that it generally accords with other personality assessment tools (Fehr et al., 1992; Wrightsman, 1991; Panitz, 1989; McHoskey et al., 1998; McHoskey, 1999; McHoskey and Hicks, 1999).

We included the Mach scale with the goal of controlling for variations in inherent predispositions toward trusting or trustworthy behavior. It is arguably ambiguous whether amount sent should increase or decrease with a participant's Mach score, ${ }^{9}$ but since the Mach score has also been found to measure subjects' willingness to engage in manipulative or exploitative behaviors we unambiguously expect a high Mach score to be associated with a low amount returned. In previous related work, Meyer (1992) found evidence suggesting high Machs are less likely to reject low offers in the ultimatum game, while Gunnthorsdottir et al. (2000), using a modified trust game, found high Machs did reciprocate less.

A second set of questions was adapted from Glaeser et al. (2000) to supplement the Mach scale with questions relating more directly to subjects' social-connectedness, or "social capital". We asked the following questions eliciting Likert and numerical responses:

Friends: how many friends do you have whom you would consider close?

Trust strangers: when dealing with strangers, one is better off using caution before trusting them.

Little at stake: how much do you tend to trust others when you have a little at stake?

Lot at stake: how much do you tend to trust others when you have a lot at stake?

Lend money: how often do you lend money to friends?

Lend possessions: how often do you lend personal possessions to friends?

Table 4 presents the summary statistics on all the trust-related questions in our survey.

\subsection{Predicting the amount sent}

We report the results of regressions of amount sent on individual characteristics in Table 5. Columns (1)-(5) build incrementally to a model including all the demographic variables and

\footnotetext{
${ }^{8}$ The points are summed over the 20 questions, and a constant of 20 is added to generate a measure that ranges between 40 and 160, with the neutral score at 100 .

${ }^{9}$ Gunnthorsdottir et al. (2000) argue that the cynicism of high Machs plus the general tendency for noncooperators to think others are like them both suggest trust should decrease with the Mach score. On the other hand, these authors note that high Machs tend to be more risk seeking than lows which might suggest trust should increase with the Mach score (Christie and Geis, 1970).
} 
Table 4

Summary statistics for social-connectedness variables

\begin{tabular}{|c|c|c|c|c|c|c|}
\hline \multirow[t]{2}{*}{ Variable } & \multicolumn{2}{|c|}{ Control $(n=44)$} & \multicolumn{2}{|c|}{ NO PRIOR $(n=46)$} & \multicolumn{2}{|c|}{ PRIOR $(n=40)$} \\
\hline & Mean & S.D. & Mean & S.D. & Mean & S.D. \\
\hline TRUST STRANGERS & 4.89 & 1.04 & 4.76 & 1.16 & 5.08 & 0.94 \\
\hline LITTLE AT STAKE & 3.32 & 0.80 & 3.37 & 0.64 & 3.25 & 0.63 \\
\hline LOT AT STAKE & 2.00 & 0.72 & 2.24 & 0.88 & 2.18 & 0.71 \\
\hline LEND MONEY & 2.61 & 0.89 & 2.78 & 0.87 & 2.63 & 0.87 \\
\hline POSSESSIONS & 1.91 & 0.91 & 2.15 & 0.87 & 2.05 & 0.90 \\
\hline FRIENDS & 9.84 & 5.89 & 8.75 & 6.00 & 7.59 & 4.79 \\
\hline $\mathrm{MACH}$ & 90.50 & 16.05 & 91.91 & 17.74 & 94.38 & 16.38 \\
\hline
\end{tabular}

the Mach score. Details on variable definitions are included in Appendix B. Three results are important.

First, the coefficient on the 2RT-P dummy remains negative and statistically significant in all regressions. The negative effect of prior knowledge of playing both roles appears to be quite robust, even controlling for inherent dispositions toward trusting and trustworthy behavior using the Mach scale. The magnitude varies little across regressions, consistent with random assignment to treatment group.

Second, among our subjects, high Machs display considerably less trust than low Machs. This effect is weakened only by the inclusion of the second set of questions on trust and

Table 5

Amount sent regressions

\begin{tabular}{|c|c|c|c|c|c|}
\hline & (1) & (2) & (3) & (4) & (5) \\
\hline Constant & $13.34^{* *}(1.79)$ & $13.21^{* *}(1.63)$ & $15.98^{* *}(2.80)$ & $15.94^{* *}(2.86)$ & $11.72 *(5.10)$ \\
\hline NO PRIOR & $-0.75(1.05)$ & $-1.16(0.98)$ & $-1.17(1.01)$ & $-1.03(1.06)$ & $-0.95(1.01)$ \\
\hline PRIOR & $-2.45^{*}(1.04)$ & $-2.53^{* *}(0.93)$ & $-2.48^{* *}(0.94)$ & $-2.33^{*}(1.00)$ & $-2.04 *(0.97)$ \\
\hline EXPERIMENTER & $1.68^{*}(0.72)$ & $1.74^{* *}(0.67)$ & $1.66^{*}(0.69)$ & $1.63^{*}(0.69)$ & $1.35^{+}(0.71)$ \\
\hline $\mathrm{MACH}$ & $-0.08^{* *}(0.02)$ & $-0.06^{* *}(0.02)$ & $-0.06^{* *}(0.02)$ & $-0.06^{* *}(0.02)$ & $-0.03^{+}(0.02)$ \\
\hline NONWHITE & - & $-4.14^{* *}(0.73)$ & $-4.44^{* *}(0.78)$ & $-4.51^{* *}(0.84)$ & $-3.33^{* *}(1.06)$ \\
\hline FEMALE & - & $-1.21^{*}(0.61)$ & $-1.17^{+}(0.62)$ & $-1.23^{*}(0.62)$ & $-0.94(0.63)$ \\
\hline MEDU & - & - & $0.07(0.21)$ & $0.09(0.21)$ & $0.11(0.20)$ \\
\hline FEDU & - & - & $-0.24(0.22)$ & $-0.27(0.23)$ & $-0.31(0.25)$ \\
\hline LOWINCOME & - & - & - & $0.35(0.96)$ & $-0.14(0.96)$ \\
\hline HIGHINCOME & - & - & - & $0.75(0.97)$ & $0.71(0.95)$ \\
\hline TRUST STRANGERS & - & - & - & - & $-0.37(0.38)$ \\
\hline LITTLE AT STAKE & - & - & - & - & $1.25^{+}(0.64)$ \\
\hline LOT AT STAKE & - & - & - & - & $0.12(0.49)$ \\
\hline LEND MONEY & - & - & - & - & $-0.41(0.43)$ \\
\hline POSSESSIONS & - & - & - & - & $0.37(0.40)$ \\
\hline FRIENDS & - & - & - & - & $0.01(0.05)$ \\
\hline$R^{2}$ & 0.21 & 0.34 & 0.35 & 0.36 & 0.41 \\
\hline
\end{tabular}

OLS with robust standard errors, dependent variable = amount sent.

+ Significant at 0.10 level.

* Significant at 0.05 level.

** Significant at 0.01 level. 
social-connectedness, which we would expect to be collinear with the Mach score and absorb some of the variation in amounts sent.

Third, non-whites in our sample exhibited significantly less trust than whites. This effect also appears to be quite robust. Our non-white variable is simply a dummy variable taking value zero if the subject identified herself as white and one if she identified herself as Latino/Hispanic, African-American, Asian-American, American Indian or other. One possible explanation for this effect is that people display less trust of strangers in environments dominated by cultural or ethnic groups other than their own. Given this interpretation, our results are consistent with Fershtman and Gneezy (2001), who find different amounts of trust are extended depending on the observable ethnic background of a sender's partner. In our case, participants did not observe the race or ethnicity of their partner; the probability was high, however, that the partner would be white.

Women appear to send less than men, but this effect is not robust. It is marginally significant in Columns (1)-(4) and insignificant in the last regression. Family background appears to have little power in predicting the extent of trusting behavior. The variables on social-connectedness are also largely insignificant. The one exception is the little at stake trust variable; it is marginally significant, indicating that people's self-reports of trust predict trusting behavior in the laboratory to some extent, but only when the question matches the stakes of the game. ${ }^{10}$ Addition of the social-connectedness questions dilutes the power of the Mach score to predict trust, as we might expect. ${ }^{11}$

\subsection{Predicting the fraction returned}

We report results of regressions of fraction returned on individual characteristics in Table 6. We begin in Columns (1)-(3) with the simplest possible regressions of fractions returned on experimental conditions and then build incrementally to a model that includes personal characteristics of the players. We include the amount received by the returner (i.e. three times the amount sent) as an explanatory variable, to test the hypothesis that people respond generously to being trusted and return a larger fraction to senders who have been trusting. ${ }^{12}$

Four points are important to note. First, the coefficients on the dummies for the 2RT-NP and 2RT-P treatments remain negative and significant. Second, in contrast to the results on amounts sent, non-whites are not significantly less likely to reciprocate in our sample than whites. Third, while Mach scores did appear to be powerful predictors of trust, they

\footnotetext{
$\overline{10}$ One might also worry that this question correlates well with behavior because it provides a form of debriefing for the participant rather than because it predicts behavior. That is, saying one does not trust much when the stakes are low after not having trusted may reduce dissonance.

11 Note that there are two potential econometric problems with the regressions reported earlier. The first is that the dependent variable is censored: amounts sent are limited to the interval $[0,10]$. The second is that the dependent variable is discrete rather than continuous: participants could only send whole dollar amounts. We estimated an ordered logit model to correct for both problems and found results consistent with the reported OLS regressions. These estimates are available from the authors.

12 If the amount received by the returner was zero, we treat the fraction returned by the returner as a missing value, since the returner had no choice to make. Assuming that our regression model is correctly specified, this censoring on an independent variable will not bias our coefficient estimates.
} 


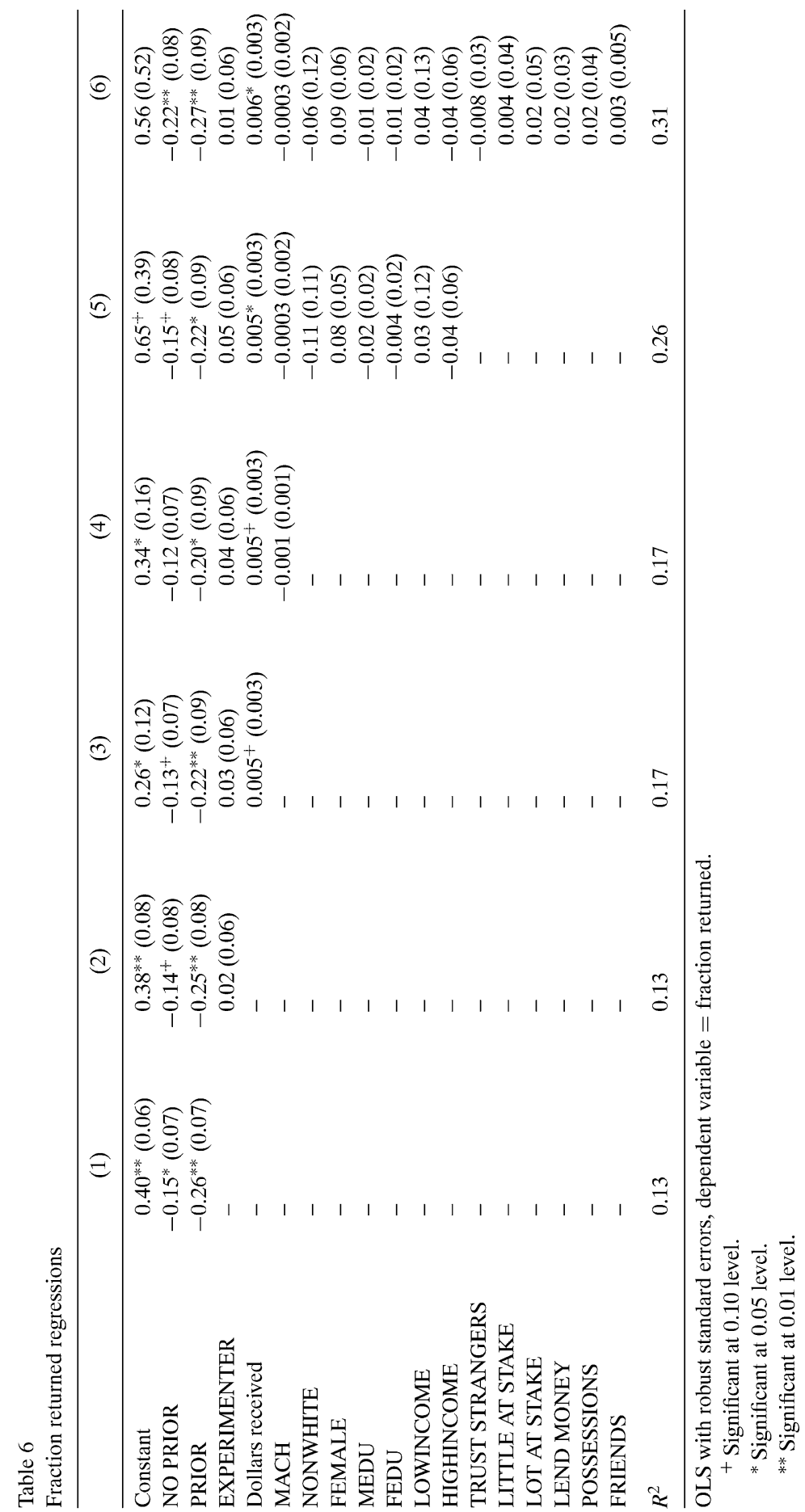


do not predict reciprocity or trustworthiness. Fourth, it does appear that returners respond generously to being trusted, although the effect is small in economic terms. A US\$ 3 increase in the amount the returner receives (a US\$ 1 increase in amount sent) leads to an increase in fraction returned of approximately 1.7 percent. In addition, while women appear to return a slightly larger fraction than men, the result is not significant.

\section{Concluding remarks}

Playing both roles in the trust game appears to reduce both overall trust and overall reciprocity. Our evidence both on amounts sent and on amounts returned in the trust game strongly rejects the golden rulehypothesis. In the introduction, we suggested the alternative hypothesis, consistent with subjects' comments on two open-ended questions on the exit questionnaire, that subjects feel less obligation to their counterparts in the two-role protocols because they know that their counterpart will have more than one opportunity to make money in the game-the reduced responsibility hypothesis. There may, however, be other reasons why playing both roles would reduce trust and reciprocity in the trust game. ${ }^{13}$ The reduced responsibilityhypothesis should be tested directly against plausible alternatives in future experiments. It would be important in this context, for instance, to investigate the relationship between our two-role game and a "two-way" trust game in which subjects play both roles with the same counterpart. ${ }^{14}$

It is worth emphasizing our result that the Mach score predicts a lack of trust, but does not predict trustworthiness. This contrasts with the findings of Gunnthorsdottir et al. (2000), who observed no correlation between Mach scores and trust, but found a negative correlation between higher Mach scores and trustworthiness. ${ }^{15}$ Our goal in using the Mach scale was to measure and control for any inherent dispositions toward trusting or trustworthy behavior. These seemingly divergent findings suggest that while the Mach scale holds some promise for this purpose, it should be used with caution until further work makes it clearer under what conditions and to what extent it is useful in economic experiments.

\section{Acknowledgements}

We thank Mike Belzer and Corinna Noelke for their help in running the experiments, Laura Burks for data assistance, Sam Bowles, Ernst Fehr, Herb Gintis, George Akerlof and Matthew Rabin for helpful conversations, and Martin Dufwenberg, Rachel Croson, Nat Wilcox, an anonymous referee, and participants at the 2000 Economic Science Association meeting for helpful comments. This research is funded by MacArthur Foundation's Norms and Preferences Network. Additionally, Carpenter acknowledges the support of the National

\footnotetext{
13 This particular alternative hypothesis suggests that subjects send and return less because self-interest motivations overcome fairness motivations when playing both roles. But, as noted by a referee, there is another alternative: playing both roles may cue subjects to follow norms from competitive game-playing and under this set of norms it may be seen as fair, rather than selfish, to compete aggressively by sending and returning less.

14 A similar concept is developed in Konow (2000) to explain deviations from fairness in allocation games.

15 However, the results are not directly comparable because the games, the protocols and the methods of measurement differ (Gunnthorsdottir et al., 2000).
} 
Science Foundation (SES-CAREER 0092953) and Verhoogen the support of the MacArthur Research Network on the Costs of Inequality.

\section{Appendix A. Sample instructions for 2RT-NP treatment}

\section{A.1. Instructions (for all participants)}

You have been asked to participate in an economics experiment. The instructions we are about to read are self-explanatory. If, after we have read through the instructions, you still have questions, please raise your hand and someone will come by to help you. Now that the experiment has begun, we ask that you do not talk, at all, during the experiment.

In this experiment, each of you will be paired with a different person who is in another room. You will not be told who this person is either during or after the experiment nor will they be told who the others are. All participants in the experiment, regardless of what room they are in, are currently reading the same set of instructions. The two rooms will be referred to later as rooms A and B. Please look at the board at the front of the room to see which room you are in.

You will notice that there are other people in the same room with you who are also participating in this experiment. You will not be paired with any of these people. There is also a person in each room, called a monitor. Monitors will be in charge of the experiment as explained later.

Each person in room A and each person in room B will be allocated US\$ 10 as a show-up fee for participating in this experiment. Persons in room A will have the opportunity to send in an envelope, some, all, or none of their show-up fee to a person in room B. Each dollar sent to room B will be tripled. For example, if a person in room A sends an envelope which contains US\$ 4, the envelope will contain US\$ 12 when it reaches room B. If a person in room A sends an envelope that contains US\$ 9, the envelope will contain US\$ 27 when it reaches room $\mathrm{B}$. The person in room $\mathrm{B}$ will then decide how much money to send back to the person in room $\mathrm{A}$ and how much money to keep.

The remainder of these instructions will explain exactly how this experiment is run. This experiment is structured so that no one, including the monitors, will know the personal decisions of people in either room A or B. Since your decision is private, we ask that you do not tell anyone your decision either during or after the experiment.

The experiment is conducted as follows: a number of large unmarked envelopes have been placed in a box at the front of room A. Each of these envelopes contains 10 US\$ 1 bills (the show-up fee for a person in room A) and a smaller envelope marked with a number. The monitor in room A will choose one person at a time, and let them pick an unmarked envelope from the front of the room. Once a person has an envelope, he or she will go to the back of the room, privately open the unmarked envelope and place as many dollar bills in the smaller envelope as they want, keeping the rest. Only the person who opened the envelope will know which number was on the smaller envelope. If you are in room A, remember this number (to help you remember, there will be a small pad of paper and a pen at the decision tables so that you can write down the number). This process will continue until everyone in room A has made his or her decision. 
Each person in room A must decide how many dollar bills to put in the smaller envelope. The person then keeps the remaining dollar bills. Examples: (1) put US\$ 2 in the smaller envelope and keep US\$ 8; (2) put US\$ 9 in the smaller envelope and keep US\$1. These are examples only; the actual decision is up to each person.

Once a person in room A has made a decision he or she should put the smaller envelope back into the larger, unmarked envelope, and return the unmarked envelope to the box marked return envelopes. Notice that each returned envelope will look exactly the same.

After all the envelopes have been put in the return box, monitor A will transport the box to a recorder in the hallway. The recorder will then, one at a time, take the smaller envelopes out of the larger envelopes, record on a sheet of paper the number of the smaller envelope and the amount of money inside the envelope. The recorder will then triple the amount of money in the smaller envelope and place the smaller envelope back into the larger envelope. At this point, the recorder will transfer the envelopes to room B.

Monitor B will then give each person in room B, one at a time, an unmarked envelope from the front of the room. The person who was called on will then go to the back of the room to privately open the larger envelope. Each person in room B must decide how many dollar bills to leave in the smaller envelope. The person keeps the remaining dollar bills. The smaller envelope should then be placed in the larger envelope and the larger envelope should be placed in the return envelopes box. If you are in room B, remember the number of the envelope that you receive (to help you remember, there will be a pad of paper and a pen at the tables in the back of the room so that you can write down this number). When everyone in room B has had the opportunity to make his or her decision, the box of returned envelopes will be carried to the recorder in the hallway. The recorder will then, one at a time, open the larger envelopes and record how much is in the smaller envelope. After recording how much was in the smaller envelope, the recorder will seal the envelope. When all the small envelopes have been recorded and sealed, the recorder will place them back in the box and bring them back to room A.

Before the envelopes are returned in room A, everyone (in both the rooms) will be asked to fill out a short questionnaire. At the top of the questionnaire you will be asked for the envelope number and the room letter you were in. Please do not forget to include this information. Once you have finished the questionnaire, you will be asked to put it in a box at the front of the room to assure your anonymity. At this point, the session is over for those people in room B and they will be free to leave.

After the questionnaires have been completed, monitor A will choose one person at a time to go to the box marked return envelopes to retrieve the smaller envelope with the appropriate number marked on it. Do not open your envelope yet. This process will continue until every one in room $\mathrm{A}$ has retrieved his or her envelope and returned to his or her seat. When everyone is finished, monitor A will ask if everyone has retrieved the correct envelope. If the people have all taken the correct envelope, then the experiment is finished. If, however, an envelope has ended up with the wrong person in room A, then monitor A will collect all the smaller envelopes again and the process will repeat until everyone has the correct envelope.

Please raise your hand if you have any questions regarding how the experiment will proceed. 


\section{A.2. Additional instructions for all participants}

Recall that this is room A. While the participants in this room were making choices about how much of their US\$ 10 to send to the other room, the participants in the other room were also choosing how much to send to this room. That is, both of the rooms were room As. Now, both rooms will be room Bs. Each of you will now be given an envelope and will complete the role of a player in room B. That is, each of you will have the chance to go to the back of the room to decide how much money to keep and how much to send back to a participant in the other room. Likewise, the participants in the other room will now decide how much to send back to this room.

You will be chosen, one at a time, to make your decision at the back of the room. There is one thing to keep in mind; it is very unlikely that the envelope you open at the back of the room comes from the same person who is currently opening the envelope that you sent to room B. That is, you are not likely to have sent an envelope to the same person you are currently receiving an envelope from.

Lastly, you will now need to keep track of a second number. You were asked to remember the number of the smaller envelope that you sent as a person in room A, and now you must also remember the number of the envelope that has been passed to you as a person in room B. Again, there is a pad of paper at the back of the room so that you can write these numbers down. We suggest that you organize the numbers as follows:

as a participant in room $\mathrm{A}$ - envelope\# as a participant in room $\mathrm{B}$ - envelope\#

Remember, only you will ever know what these numbers are, so when you make your choices they are anonymous. If you have any questions, please raise your hand.

\section{Appendix B. Data appendix}

The variables that appear in the regression results are defined as follows:

NO PRIOR:

PRIOR:

EXPERIMENTER:

MACH:

NONWHITE: takes the value of 1 for observations from 2RT-NP treatment, 0 otherwise.

takes the value of 1 for observations from 2RT-P treatment, 0 otherwise.

takes the value of 1 if one of the experimenters read instructions aloud to the subject, 0 if the other experimenter read the instructions.

index constructed from 20 survey questions. Scaled from 20 to 160. See Christie and Geis (1970), Fehr et al. (1992) for details. takes the value 1 if subject self-identified as Latino/Hispanic, African-American, Asian-American, American Indian, or wrote in a non-Caucasian ethnic identity on exit survey. Takes value 0 if otherwise. 
FEMALE:

MEDU:

FEDU:

LOWINCOME:

HIGHINCOME:

TRUST STRANGERS:

LITTLE AT STAKE:

LOT AT STAKE:

LEND MONEY:

POSSESSIONS:

FRIENDS: takes value 1 if female, 0 if male.

takes value 10 if respondent's mother only completed some high school, 12 if she got a high school diploma, 14 if she attended college, 16 if she completed college, 17 if some advanced training, 18 if she attained an advanced degree. takes value 10 if respondent's father only completed some high school, 12 if he got a high school diploma, 14 if he attended college, 16 if he completed college, 17 if some advanced training, 18 if he attained an advanced degree. takes value 1 if respondent reported family household income as US\$ 0-20,000 or 20,000-40,000. Takes value 0 otherwise. takes value 1 if respondent reported family household income as more than US\$200,000. Takes value 0 otherwise.

records responses to the statement "when dealing with strangers, one is better off using caution before trusting them." Takes value 1 if respondent reports "disagree strongly," 2 if "disagree somewhat," 3 if "disagree slightly," 4 if "agree slightly," 5 if "agree somewhat," 6 if "agree strongly." records responses to the question, "how much do you tend to trust others when you have a little at stake?" Takes value 1 if respondent reports "not at all," 2 if "a little," 3 if "some," 4 if "a lot."

records responses to the question, "how much do you tend to trust others when you have a lot at stake?" Takes value 1 if respondent reports "not at all," 2 if "a little," 3 if "some," 4 if "a lot."

records responses to the question, "how often do you lend money to friends?" Takes value 1 if respondent reports "more than once a week," 2 if "about once a week," 3 if "about once a month," 4 if "once a year or less."

records responses to the question, "how often do you lend personal possessions to friends?" Takes value 1 if respondent reports "more than once a week," 2 if "about once a week," 3 if "about once a month," 4 if "once a year or less."

records responses to the question, "how many friends do you have whom you would consider close?" Takes value of number of friends reported.

\section{References}

Barr, A., 1999. The Effects of Social Disruption on Bargaining and Investment Behavior: An Experimental Study from Zimbabwe. Centre for the Study of African Economies, University of Oxford, mimeo.

Berg, J., Dickaut, J., McCabe, K., 1995. Trust, reciprocity and social history. Games and Economic Behavior 10, $122-142$. 
Binmore, K., Shaked, A., Sutton, A., 1985. Testing noncooperative bargaining theory: a preliminary study. American Economic Review 75, 1178-1180.

Bolle, F., 1998. Rewarding trust: an experimental study. Theory and Decision 45, 83-98.

Bolton, G., Ockenfels, A., 1999. ERC: a theory of equity, reciprocity and competition. American Economic Review 90, 166-193.

Brandts, J., Charness, G., 2000. Hot versus cold: sequential responses and preference stability in experimental games. Experimental Economics 2, 227-238.

Carpenter, J., 2002. Information, Fairness and Reciprocity in the Best Shot Game. Economics Letters 75 (2002) 243-248.

Carter, J., Irons, M., 1991. Are economists different, and if so, why? Journal of Economic Perspectives 5 (2), 171-177.

Christie, R., Geis, F., 1970. Studies in Machiavellianism. Academic Press, New York.

Cox, J., 1999. Trust, Reciprocity, and Other-Regarding Preferences of Individuals and Groups. Department of Economics, University of Arizona, mimeo.

Eckel, C., Grossman, P., 1996. Altruism in anonymous dictator games. Games and Economic Behavior 16, 181191.

Fahr, R., Irlenbusch, B., 1999. Fairness as a constraint on trust and reciprocity: earned property rights in a reciprocal exchange experiment. Economics Letters 66, 275-282.

Falk, A., Fischbacher, U., 1998. A Theory of Reciprocity. Institute for Empirical Economics, University of Zurich, mimeo.

Fehr, E., Schmidt, K., 1999. A theory of fairness, competition and cooperation. Quarterly Journal of Economics 114, 769-816.

Fehr, B., Samson, D., Paulhus, D., 1992. The Construct of Machiavellianism: Twenty Years Later, In: Spielberger, C., Butcher, J. (Eds.), Advances in Personality Assessment. Lawrence Erlbaum, Hillsdale, pp. 77-116.

Fershtman, C., Gneezy, U., 2001. Trust and discrimination in a segmented society. Quarterly Journal of Economics 116, 351-377.

Forsythe, R., Horowitz, J., Savin, N., Sefton, M., 1994. Fairness in simple bargaining experiments. Games and Economic Behavior 6, 347-369.

Frohlich, N., 1992. An impartial reasoning solution to the prisoner's dilemma. Public Choice 74, 447-460.

Frohlich, N., Oppenheimer, J., 1996. Experiencing impartiality to invoke fairness in the n-PD: some experimental results. Public Choice 86, 117-135.

Glaeser, E., Laibson, D., Scheinkman, J., Soutter, C., 2000. What is social capital? The determinants of trust and trustworthiness. Quarterly Journal of Economics 115, 811-846.

Gueth, W., Tietz, R., 1990. Ultimatum bargaining behavior: a survey and comparison of experimental results. Journal of Economic Psychology 11, 417-449.

Gueth, W., Schmittberger, R., Schwarz, B., 1982. An experimental analysis of ultimatum bargaining. Journal of Economic Behavior and Organization 3, 367-388.

Gueth, W., Ockenfels, P., Wendel, M., 1997. Cooperation based on trust: an experimental investigation. Journal of Economic Psychology 18, 15-43.

Gunnthorsdottir, A., McCabe, K., Smith, V., 2000. Using the Machiavellian Instrument to Predict Trustworthiness in a Bargaining Game. Department of Economics, University of Arizona, mimeo.

Hoffman, E., McCabe, K., Shachat, J., Smith, V., 1994. Preferences, property rights, and anonymity in bargaining games. Games and Economic Behavior 7, 346-380.

Hoffman, E., McCabe, K., Smith, V., 1996. Social distance and other-regarding behavior in dictator games. American Economic Review 86, 653-660.

Kahneman, D., Knetsch, J., Thaler, R., 1986. Fairness and the assumptions of economics. Journal of Business 59 , s285-s300.

Konow, J., 2000. Fair shares: accountability and cognitive dissonance in allocation decisions. American Economic Review 90, 1072-1091.

McCabe, K., Smith V., LePore, M., 1998. Intentionality Detection and "Mindreading": Why Does Game Form Matter? Department of Economics, University of Arizona, mimeo

McHoskey, J., 1999. Machiavellianism, intrinsic versus extrinsic goals, and social interest: a self-determination theory analysis. Motivation and Emotion 23, 267-283.

McHoskey, J., Hicks, B., 1999. Machiavellianism, adjustment and ethics. Psychological Reports 85, 138-142. 
McHoskey, J., Worzel, W., Szyarto, C., 1998. Machiavellianism and psychopathy. Journal of Personality and Social Psychology 74, 192-210.

Meyer, H., 1992. Norms and self-interest in ultimatum bargaining: the prince's prudence. Journal of Economic Psychology 13, 215-232.

Panitz, E., 1989. Psychometric investigation of the Mach IV scale measuring Machiavellianism. Psychological Reports 64, 963-968.

Rabin, M., Charness, G., 1999. Understanding Social Preferences with Simple Tests; Forthcoming in Quarterly Journal of Economics.

Snijders, C., Keren, G., 1994. Giving Trust and Honoring It: An Experimental Test of Two Utility Transformations. University of Utrecht, mimeo.

Weg, E., Smith, V., 1993. On the failure to induce meager offers in ultimatum games. Journal of Economic Psychology 14, 17-32.

Wilson, D., Near, D., Miller, R., 1996. Machiavellianism: a synthesis of the evolutionary and psychological literatures. Psychological Bulletin 119, 285-299.

Wilson, D., Near, D., Miller, R., 1998. Individual differences in Machiavellianism as a mix of cooperative and exploitative strategies. Evolution and Human Behavior 19, 203-212.

Wrightsman, L., 1991. Interpersonal Trust and Attitudes Towards Human Nature. In: Robinson, J., Shaver, P., Wrightsman, L. (Eds.), Measures of Personality and Social Psychological Attitudes. Academic Press, San Diego, pp. 373-412. 